\title{
Sample Size and the Reef/Santa Cruz Lapita Sequence
}

\author{
Peter Sheppard and Roger Green
}

\author{
Department of Anthropology, \\ The University of Auckland, \\ Private Bag 92019, Auckland, New Zealand. \\ p.sheppard@auckland.ac.nz; pounamu@ihug.co.nz
}

\begin{abstract}
A fundamental problem in archaeology is the nature of our samples and sampling (Orton 2000). Although this encompasses issues ranging from the transformation of dynamic behavioural systems into static archaeological records, to the subsequent taphonomic effects which over time alter that record, at the most basic level we can ask the question: All else being equal, what is the effect of where and how much we dig in a site? Ultimately this reflects the specific question we wish to ask of the site and the structure of the particular data type under investigation. If we are interested in a behaviour which is only represented by very rare data associated with specific contexts of unknown distribution in the site then we might need to excavate very large samples and hopefully find ways to identify and target the specific context. Alternatively, if we are looking for abundant data which are randomly distributed across the site, then a small sample employing a stratified systematic unaligned strategy or some similar approach might suffice. Pottery sherds have, of course, always been popular as they preserve well and are usually found in large quantities. We generally assume that the original population of pots was fragmented and preserved in a similar fashion. Of course this is problematic as it stands to reason that large pots will generate more fragments than small pots, thick sherds will preserve better than thin sherds, rim sherds better than body sherds, etc. Such variation may be of little importance for many studies. However, if the question relates to the study of pottery decoration which is to be used for chronological seriation, then we should consider the full range of factors which might influence the variation of decorative classes within sites, assemblages, and samples.

At the most basic level a very small sherd sample of a large target assemblage might provide a very poor sample; however if there was no variation in the assemblage, then 1 sherd is as informative as 1000, and would provide the same answer in a seriation. If on the other hand there were a large number of motifs in the large target assemblage, then a small sample could seriously under-estimate both the total number of motifs
\end{abstract}


present and the motif proportions in the assemblage - a very poor piece of data in a seriation. This is the familiar sample size - richness problem. If knowing how many motifs are actually present in a target assemblage is critical to the analysis, then we need to be confident that our sample is large enough to reasonably estimate the number of motifs, all else being equal. Of course all else is often not equal. Ceramic deposition throughout a site is not uniform. Almost by definition sites have low densities of ceramics on the edge and varying densities throughout the site area. Even if the entire site was occupied over one short time period or comprised a series of samples each derived from separate layers within any given site (an absolutely necessary assumption in seriation), then there may be unknown structure in the distribution of sherds. For example, cooking pots may have a different spatial distribution than serving ware. Therefore, beyond simple sample size we need to consider how our sample relates to total site area and consider if unknown structure in the site might have been poorly sampled. This problem might also correlate with the issue of differential preservation or representation of motifs. As noted above, variation in pot form which could correlate with motif, might result in some motifs being under-represented e.g. motifs associated with thin pots may be under-represented as the sherds are too small for the motif to be recorded. Finally the analyst needs to consider what effect under-representation of motif numbers might have on the results of the analysis. If, for example, rare motifs have very little influence on the outcome of the seriation method, then their under-estimation will not be a problem. In this paper we will further discuss ceramic sampling issues relating to the Reef/Santa Cruz Lapita sites in the Outer Eastern Islands of the Solomons excavated in the early 1970s as part of the Southeast Solomons Culture History Project (Green 1976). These were among the first and largest well excavated Lapita sites and their analysis and position on the western edge of Remote Oceania has made them central to discussions of the definition of the Lapita Complex and its movement into the Pacific (Green 1979, 1987, 1991a, 1991b, 1992, 2003; Sheppard and Green 1991; Sheppard and Walter 2006).

In the Pacific we often have small poorly preserved ceramic samples which have very poorly understood relationships to the target population (site, context) from which they are derived. This subject has most recently been critically reviewed by Felgate (2003), although other authors have attempted to address issues of ceramic sample size and comparability in Lapita assemblages (Anson 1987; Chiu 2003:250-254; Kirch et al. 1987). Felgate dealt specifically with our ability to generate chronological seriations using available Lapita ceramic data sets and concluded that our ability to work with the data was very limited. Although Felgate (2003:85) noted the Reef/Santa Cruz dataset was among the best available, he felt it too needed to be used with caution, especially when making comparisons beyond the Reef/Santa Cruz region. A more pointed critique has come from Best (2002) who has argued that the seriation and more generally the chronological sequence proposed for the Lapita sites (SE-SZ-8, SE-RF-2, SE-RF-6) excavated by Green is in fact wrong.

Simon Best (2002:91) has legitimately raised issues that should be addressed with respect to the initial databases for motifs from Lapita sites SE-SZ-8, SE-RF-2 and SE-RF-6. They apply to both presence/absence and to frequency counts. His claims reduce essentially to two concerns:

(a) Best avers the samples recovered through excavation are in fact non-representative when sampling the results of human behaviour, given the enormous disparity in percentage terms of the area of each site and the at times fairly small areas actually subjected to excavation. More generally this is a question of sampling, through excavation, of unknown but potentially complex spatial structure within ceramic data variation across the site.

(b) Best also deduces that the number of motifs recorded for each site during their recording by Donovan in 1972-73 is directly proportional to the actual areas excavated at that time, and that it is this factor in large part which controls their frequency. Thus any changes in motif frequencies between sites do not reflect chronological differences in their age as was claimed by (Donovan 1973) and subsequent analysts building on her records. More generally then this is a question of sample size, motif richness and sample comparability. 
The conclusion drawn from these contentions by Best is that it is simply not possible to demonstrate any ordering of sites SE-SZ-8, RF-2 and RF-6 on the basis of their motif content. All attempts to do so, whether based on presence / absence as with Green (1978), or on frequency (Anson 1986, 1987), are flawed and these or other analyses employing such data for temporal or similarity purposes have limited potential for revealing outcomes of significance when carrying out comparative analyses.

In the following we provide the early 1970s motif database under consideration, published here in full for the first time. We then discuss issues of site sampling and structure ${ }^{1}$ and conclude with evaluation of the sample size effect on motif richness.

\section{The Dataset and Site Sampling}

In the late 1960s and early 70s sampling issues were becoming very important in archaeology (Asch and Mueller 1975; Redman 1974) and the Reef/Santa Cruz sites were excavated with these problems in mind. As a result the sampling strategies were state of the art and must still rate amongst the better site samples available for the Lapita period, given the logistic and preservation issues which continue to make sampling of these sites difficult.

It is perhaps ironic that given the explicit sampling strategies employed in the excavation of the Reef/ Santa Cruz sites and the comparatively large absolute numbers of sherds recovered, that these datasets should now be considered problematic. In particular the fact that a very large portion of the small RF-2 site (Table 1) was eventually excavated in two separate investigations would now almost appear to be a handicap as it might make comparison with the samples from the other two very much larger sites questionable. Excavation of RF2 was conducted after a systematic surface collection of ceramics from over $676 \mathrm{~m}^{2}$ or $61 \%$ of the site's area. Following this in February 1971 the central portion of the site was targeted for excavation which consisted of an irregular central area of $64 \mathrm{~m}^{2}$ and a few outlying $4 \mathrm{~m}$ sized squares for a total of $72 \mathrm{~m}^{2}$. This actually subsampled a range of the central squares with different densities of surface sherds $\left(21 \mathrm{~m}^{2}\right.$ where the frequency was greater than 20,18 $\mathrm{m}^{2}$ where the frequency was less than 10 surface sherds per $\mathrm{m}^{2}$, and $33 \mathrm{~m}^{2}$ where the

Table 1. Comparisons of survey and excavation strategies on three Lapita sites in 1971 (with revisions from Green 1976 Table 18).

A. Survey and Excavation Details

\begin{tabular}{llll}
\hline Site Number & \multicolumn{1}{c}{ SE-RF-6 } & \multicolumn{1}{c}{ SE-RF-2 } & \multicolumn{1}{c}{ SE-SZ-8 } \\
\hline Nearest Modern Village & Ngamanie & Nenumbo & Nanggu \\
Approx. Dimensions of Site $(\mathrm{m})$ & $40 \times$ an estimated 60 & $25 \times 25$ & $100 \times 250$ \\
Total Estimated Area in $1971\left(\mathrm{~m}^{2}\right)$ & c. $2400+.{ }^{(i)}$ & 1105 & c.14,000 \\
Sampling Area $\left(\mathrm{m}^{2}\right)$ & 180 & 106 & 459 \\
Excavated Area in $1971\left(\mathrm{~m}^{2}\right)$ & 20 & $72^{(i)}$ & 51 \\
\hline
\end{tabular}

B. Sampling Methods

\begin{tabular}{|c|c|c|c|}
\hline Site Number & Sample Type & Method & Shape of Sample Area Excavated \\
\hline SE-RF-2 & $\begin{array}{l}\text { Near total, or systematic } \\
\text { aligned }\end{array}$ & $\begin{array}{l}\text { Screening and analysis of content } \\
\text { of top } 3 \mathrm{~cm} \text { followed by [targeted] } \\
\text { excavation }\end{array}$ & $\begin{array}{l}\text { Guided by the surface distribution of sherds a } \\
\text { rectangular area with extensions into centre of site } \\
\text { comprising } 64 \mathrm{~m}^{2} \text { plus some outlying squares in the } \\
\text { north of the site }\end{array}$ \\
\hline SE-RF-6 & $\begin{array}{l}\text { Stratified, systematic } \\
\text { unaligned }\end{array}$ & $\begin{array}{l}\text { Random sampling of a target area } \\
\text { through a } 1 \mathrm{~m} \text { in } 9 \text { interval of } \\
\text { excavated squares }\end{array}$ & $\begin{array}{l}\text { Cross section ( } 9 \mathrm{~m} \geq 24 \mathrm{~m}) \text { at what has proved to } \\
\text { be one end of a larger site }\end{array}$ \\
\hline SE-SZ-8 & $\begin{array}{l}\text { Stratified, systematic } \\
\text { unaligned }\end{array}$ & $\begin{array}{l}\text { Random sampling of a target area } \\
\text { through a } 1 \mathrm{~m} \text { in } 9 \text { interval of } \\
\text { excavated squares }\end{array}$ & $\begin{array}{l}\text { T-shape intersecting main intersecting main axis of } \\
\text { site }\end{array}$ \\
\hline
\end{tabular}

i. In 1976 a new investigation of the surface evidence increased its length and thus the estimated size to a total of $8,400 \mathrm{~m}^{2}$.

ii. Another $81.5 \mathrm{~m}^{2}$ was excavated in 1976, making the total area finally investigated being $153.5 \mathrm{~m}^{2}$. 
frequency was fairly typical, lying between 10 and 20 sherds). The main 1971 excavation unit was bounded by squares W-P 39-40 and B-V 21-22. In 1976 an additional $81.5 \mathrm{~m}^{2}$ was excavated making the total area finally investigated $153.5 \mathrm{~m}^{2}$, or 13.9 percent of the total site area.

The resulting area has been shown to encompass both the end of a large house and an adjacent cooking area which appear to be the remains of a small hamlet or house-hold unit (Green and Pawley 1999; Sheppard and Green 1991) such as is common throughout the Pacific. It would seem most probable that this is the fundamental unit making up larger Lapita living sites (Kirch 1997:167) and the one with the greatest potential to structure ceramic variation within sites beyond simple fall-off in activity density, such as one sees at the margins of sites. The other potential source of variation within sites is of course temporal variation with large sites representing long-term occupations or horizontal palimpsest of serial or new occupations. Our study of RF-2 has indicated that within this house-hold unit there is some patterning in the form of pots, with globular cooking pots more commonly associated with the cooking area and flat bottomed bowls more commonly associated with the house area (Sheppard and Green 1991:78-79). If there is motif variation associated with this variation in form, and that remains to be determined for RF-2, then our work suggests that small test units or trenches into Lapita sites might conceivably recover a biased sample if they recover samples from only house or cooking areas. The long 1971 excavation unit which provided the ceramic sample discussed by Best and Felgate covered, though only in part, both the household and cooking area and therefore would appear to have sampled the potential range of ceramic variation in the central southern half of the site. The age of the site is well established with six statistically contemporaneous dates (Jones et al. in press) and they, together with the structural coherence of the site and the absence of any stratigraphic evidence of multiple occupations (Sheppard 1993; Sheppard and Green 1991), suggest a very limited occupation span perhaps of no more than 25 years. Thus, in the most recent paper by Jones et al. (2007) examining a probable dating for RF2, a prior of 50 years at most was employed in the Bayesian calculations. It had been thought that perhaps the northern portion of the site might represent a somewhat later stage in the site's occupation (Felgate 2003; Green 1976:255) though that unsupported supposition has now been replaced by another rather more convincing interpretation based on the different character of its probable function as a men's house, zones which were in ethnography proscribed to women (Green and Pawley 1999:78-79 \& Fig 1.9; Green ms.). Moreover, that has no bearing on the integrity of the central excavated sample of the south portion as representative of a narrow time-slice in Reef Islands Lapita prehistory. Taken together, all of these facts confirm that the RF-2 sample is very good and among the best Lapita ceramic samples available.

The SE-SZ-8 Nanggu site on the island of Santa Cruz is the largest of the three Lapita sites excavated in March 1971 by Green and at circa 14,000 $\mathrm{m}^{2}$, at the larger end of Lapita site sizes. The excavated area is located toward the centre of the southern end of this long oblong-shaped site (Green et al. nd). It should be made clear that a total area of $459 \mathrm{~m}^{2}$ was sampled with each $9 \mathrm{~m}$ block being randomly sampled and a $1 \mathrm{~m}$ square excavated. This is a systematic stratified unaligned sampling strategy which was very popular in the early 70s (Plog 1976) and has yet to be improved upon as a compromise between a purely random sampling approach and a purposive sample which takes into consideration archaeological knowledge (e.g. site boundaries, density of surface material etc.) although adaptive sampling as reviewed by Orton (2000:133) might be usefully considered today. Therefore we have a sample of motifs for an area twice the size of the total area excavated at RF-2 and, given our information on structures in RF-2, it seems probable that we have intercepted one or more household units. Further, because the sampling protocol is randomized, the motif ratios should be unbiased. It seems highly probable then that this sample is comparable, in terms of the representation of ceramic variation within the area sampled, with the RF-2 sample. This site is very large. It is likely that there are older or younger deposits elsewhere on the site, but again that is not the issue as we are simply interested in comparing areas tested in the various sites. The maximum depth of deposit in the site was $60 \mathrm{~cm}$ and although it was gardened there was no evidence of multiple occupations in the Lapita period. There was however, evidence of much 
later pits dug into the deposit. The dating of the Lapita deposits has produced statistically identical dates, providing no basis for thinking there is much time depth to the sample (Green, et al. nd).

The SE-RF-6 sherd sample is the smallest from the three sites and is the site with the smallest absolute area excavated at $20 \mathrm{~m}^{2}$. But as in SZ-8 these squares were randomly selected from $9 \mathrm{~m}^{2}$ units using a random $1 \mathrm{~m}$ in 9 interval in a rectangular strip of 9 by $24 \mathrm{~m}$ creating a stratified randomly sampled area of $180 \mathrm{~m}^{2}$. The sampled area was a cross-section across what was originally thought to be a small (40 m wide by an estimated $60 \mathrm{~m}$ long) site consisting of a band of deposit lying parallel to and back of the modern shore. After a brief excavation in February 1971, it became apparent on further investigation in 1976 that this was just one end of a site extending for circa $180 \mathrm{~m}$ along the shore. Therefore it is quite possible that earlier portions of the site exist, however whether or not the area sampled is representative of other areas of the site is not under question. The question is whether it adequately represents motif variation in the deposits created during the occupation ${ }^{2}$ of the area sampled. The area sampled is significantly larger than the area excavated in RF-2, however it is rather narrow at $9 \mathrm{~m}$. A $9 \mathrm{~m}$ wide strip dropped at random across the long axis of RF-2 could easily miss the house area and intersect the cooking area, however if it intersected a house, the area would exceed by a considerable margin even the largest dimension of the RF-2 house. Therefore the motif sample would come both from a house and the surrounding area. Clearly if there is structured motif variation within RF-6 this smaller area has a greater potential to be non-representative, however the area is large enough to ensure that the bias is less than would be the case if only a house was sampled. Moreover, the probability of a random sample at an interval of 1 in 9 from a $180 \mathrm{~m}^{2}$ strip across one end of the site seriously biasing the dominate motif ratios would seem to us to be rather low.

It is rather difficult to assess how well any sampling strategy would have sampled the sites in question given the fact that we know very little about the structure of motif variation across these or any large Lapita sites. Using the household cluster seen at RF-2 as a model of activity, which may have structured motif variation, we have considered how large an area would need to be sampled to adequately sample such a unit. If we assume that these household clusters would have produced the highest density of sherds, as seen in RF2, then Green's strategy of targeting areas of high sherd density would likely have sampled such units. All of the areas sampled are large enough to have sampled a large percentage of such a household cluster. The shape and orientation of the RF-6 site might have generated a somewhat biased sample because it intersected one end of such a unit. At present we have no way of knowing whether this is true, although consideration of pot form might be one way to investigate this possibility.

\section{Bootstrap Analysis of Sample Size}

Although evaluating the effect of the unknown structure in attribute variation across unexcavated archaeological sites is rather difficult and generally limited to assessing the scale of sampling required, there has been considerable research (Cochrane 2003; Grayson 1978; Jones et al. 1983; Kintigh 1989; Meltzer et al. 1992) into simple sample size effects. Many studies have simply looked at the correlation between sample size and number of classes recovered; more recently analysts have made increasing use of sample simulations or boot-strapping to assess the probability of the number of classes in a sample being simply the result of sample size. Put another way, these methods allow us to examine how large a sample we need to take before the increase in classes from a particular sampling distribution levels off. In the case of seriation, the point at which the distribution levels off would be the point at which the ratios of the dominant motifs, upon which the seriation would be founded, would stabilize. In the following we use such an approach to evaluate the Reef/Santa Cruz motif sample sizes.

Bootstrapping requires us to randomly sample a large number of times an empirical probability distribution based on known data and from that create a probability distribution for a parameter of interest, in this 


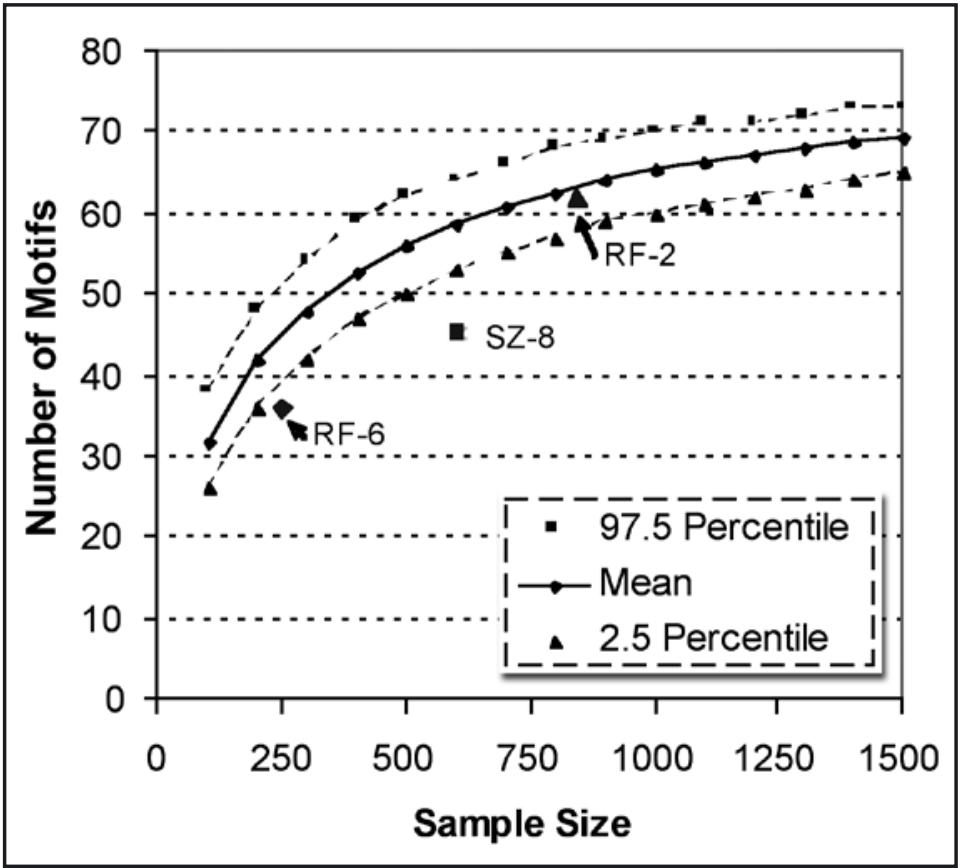

Figure 1. Results of bootstrapping simulation. case sample size. For the Reef/Santa Cruz data (Table 2) the sum of all motifs combined from the three sites was used to make an empirical probability distribution (e.g. the probability of any motif appearing in a site is proportional to the motif abundance in the combined samples from all three sites). All sites are then assumed to be equally likely to have any motif as a null hypothesis. This distribution was then randomly sampled with replacement (bootstrap) for different sample sizes (100 to 1500 motifs incremented by 100) with 10,000 samples generated for each data point ${ }^{3}$. The average of the number of motifs was calculated for each sample size and a $95 \%$ confidence interval selected (97.5 and 2.5 percentile) and plotted as shown in Figure 1.

If the number of motifs in each sample was simply a function of sample size then one would expect the samples to fall (Figure 1) near the mean number of motifs for that sample size. Both RF-6 and SZ-8 have considerably fewer motifs than would be expected under the null hypothesis, while RF-2 has an expected number of motifs based on sample size. Therefore the variation in the number of motifs between sites cannot be explained simply by sample size, given the assumption that the samples are derived and representative of a population of motifs equivalent to those found in the combined assemblages.

\section{Conclusions}

Although all of our archaeological samples could stand to be improved, as we have seen above it is rather difficult to devise the ideal sampling strategy given our need to understand site structure before we sample or excavate. All of the sites discussed here seem to have sampled adequate site areas if we use our knowledge of site RF-2 as a guide, although the RF-6 transect has the greatest potential to be non-representative of the entire site now that its true size is better appreciated. Both SZ-8 and RF-6 have considerably fewer motifs than one would expect if variation was accounted for by sample size alone. If we look at Figure 1 as providing a guide to the sample size required to adequately sample most of the motif variation in these sites, then a sample size of 500 sherds would cover $85 \%$ of the variation. If our object was to conduct a seriation, then it seems a sample of 500 sherds would have been more than adequate to sample the common motifs which would provide the basis of any seriation. Rare motifs will have contributed very little to such a seriation (Anson 1987). Although the sample size, in the analysis reported here represented by only 247 sherds would appear to be on the small side, that analysis does suggest a very real decrease in the number of motifs in the area sampled at RF-6. This result can be considered to lend support to the alternate original model of decreasing numbers of motifs in the late period of highly dentate-decorated pots consistent with a widespread pattern to be observed within the Lapita horizon; although we must now also consider the anomalously low number of motifs in SZ-8 site which based on radiocarbon dating appears to be older than RF-2. 
Table 2. A previously unpublished database listing the total frequency counts for each of the formally described Lapita motifs in the Mead/Donovan analytical system used for the percentage calculations. (NOTE: all alloforms of a motif are bundled under the general number assigned to any one motif as employed in most comparative exercises).

\begin{tabular}{|c|c|c|c|c|c|c|c|}
\hline Motif & SZ-8 (607) & RF-2 (840) & RF-6 (247) & Motif & SZ-8 (607) & RF-2 (840) & RF-6 (247) \\
\hline M1 & $19(3.13 \%)$ & $21(2.50 \%)$ & $31(12.55 \%)$ & M51 & $3(0.49 \%)$ & - & - \\
\hline M2 & $18(2.97 \%)$ & $50(5.95 \%)$ & $18(7.29 \%)$ & M52 & - & $2(0.24 \%)$ & - \\
\hline M3 & $2(0.33 \%)$ & $3(0.36 \%)$ & - & M53 & $3(0.49 \%)$ & $3(0.36 \%)$ & $3(1.21 \%)$ \\
\hline M4 & - & $1(0.12 \%)$ & - & M54 & - & $1(0.12 \%)$ & - \\
\hline M5 & $45(7.41 \%)$ & $72(8.57 \%)$ & $31(12.55 \%)$ & M55 & - & $9(1.07 \%)$ & - \\
\hline M6 & $39(6.43 \%)$ & $33(3.93 \%)$ & $21(8.50 \%)$ & M56 & $11(1.81 \%)$ & $13(1.55 \%)$ & - \\
\hline M7 & - & - & - & M57 & - & $7(0.83 \%)$ & - \\
\hline M8 & $4(0.66 \%)$ & $56(6.67 \%)$ & $10(4.05 \%)$ & M58 & - & $2(0.24 \%)$ & - \\
\hline M9 & $1(0.16 \%)$ & $16(1.90 \%)$ & - & M59 & $7(1.15 \%)$ & $4(0.48 \%)$ & - \\
\hline M10 & $2(0.33 \%)$ & $12(1.43 \%)$ & $2(0.81 \%)$ & M60 & $1(0.16 \%)$ & $12(1.43 \%)$ & - \\
\hline M11 & - & - & - & M61 & - & $2(0.24 \%)$ & - \\
\hline M12 & - & - & - & M62 & $4(0.66 \%)$ & $8(0.95 \%)$ & $2(0.81 \%)$ \\
\hline M13 & - & $4(0.48 \%)$ & - & M63 & - & $1(0.12 \%)$ & - \\
\hline M14 & $3(0.49 \%)$ & $29(3.45 \%)$ & $5(2.02 \%)$ & M64 & $4(0.66 \%)$ & $7(0.83 \%)$ & - \\
\hline M15 & - & - & - & M65 & - & $10(1.19 \%)$ & - \\
\hline M16 & $5(0.82 \%)$ & $6(0.71 \%)$ & - & M66 & - & $5(0.60 \%)$ & - \\
\hline M17 & - & $2(0.24 \%)$ & - & M67 & $21(3.46 \%)$ & $50(5.95 \%)$ & $31(12.55 \%)$ \\
\hline M18 & $28(4.61 \%)$ & $53(6.31 \%)$ & $8(3.24 \%)$ & M68 & - & $4(0.48 \%)$ & $1(0.40 \%)$ \\
\hline M19 & $61(10.05 \%)$ & $46(5.48 \%)$ & $5(2.02 \%)$ & M69 & $161(26.52 \%)$ & $56(6.67 \%)$ & $19(7.69 \%)$ \\
\hline M20 & - & - & - & M70 & $1(0.16 \%)$ & $1(0.12 \%)$ & $1(0.40 \%)$ \\
\hline M21 & - & - & - & M71 & - & $1(0.12 \%)$ & - \\
\hline M22 & - & - & - & M72 & - & $3(0.36 \%)$ & $2(0.81 \%)$ \\
\hline M23 & - & - & - & M73 & - & $3(0.36 \%)$ & - \\
\hline M24 & $26(4.28 \%)$ & $21(2.50 \%)$ & $4(1.62 \%)$ & M74 & - & $6(0.71 \%)$ & - \\
\hline M25 & - & $1(0.12 \%)$ & - & M75 & - & $4(0.48 \%)$ & - \\
\hline M26 & - & - & - & M76 & $3(0.49 \%)$ & $5(0.60 \%)$ & - \\
\hline M27 & - & $5(0.60 \%)$ & - & M77 & $33(5.44 \%)$ & $29(3.45 \%)$ & $6(2.43 \%)$ \\
\hline M28 & $9(1.48 \%)$ & $35(4.17 \%)$ & $4(1.62 \%)$ & M78 & $3(0.49 \%)$ & - & $2(0.81 \%)$ \\
\hline M29 & $11(1.81 \%)$ & $3(0.36 \%)$ & $3(1.21 \%)$ & M79 & $4(0.66 \%)$ & $35(4.17 \%)$ & $2(0.81 \%)$ \\
\hline M30 & $1(0.16 \%)$ & $20(2.38 \%)$ & $1(0.40 \%)$ & M80 & $4(0.66 \%)$ & $3(0.36 \%)$ & $2(0.81 \%)$ \\
\hline M31 & - & - & - & M81 & - & $4(0.48 \%)$ & - \\
\hline M32 & - & - & - & M82 & - & $3(0.36 \%)$ & - \\
\hline M33 & - & - & - & M83 & $1(0.16 \%)$ & $2(0.24 \%)$ & $2(0.81 \%)$ \\
\hline M34 & - & - & $1(0.40 \%)$ & M84 & - & $4(0.48 \%)$ & - \\
\hline M35 & - & - & - & M85 & - & $6(0.71 \%)$ & $1(0.40 \%)$ \\
\hline M36 & - & - & - & M86 & - & - & $2(0.81 \%)$ \\
\hline M37 & - & - & - & M87 & $1(0.16 \%)$ & - & $1(0.40 \%)$ \\
\hline M38 & - & - & - & M88 & - & - & - \\
\hline M39 & $23(3.79 \%)$ & $8(0.95 \%)$ & $2(0.81 \%)$ & M89 & $3(0.49 \%)$ & - & $2(0.81 \%)$ \\
\hline M40 & - & - & - & M90 & $2(0.33 \%)$ & - & $1(0.40 \%)$ \\
\hline M41 & - & - & - & M91 & $2(0.33 \%)$ & - & - \\
\hline M42 & - & - & - & M92 & $1(0.16 \%)$ & - & - \\
\hline M43 & - & - & - & M93 & $3(0.49 \%)$ & - & - \\
\hline M44 & - & - & - & M94 & $2(0.33 \%)$ & - & - \\
\hline M45 & - & $11(1.31 \%)$ & - & M95 & $1(0.16 \%)$ & - & - \\
\hline M46 & - & - & - & M96 & $1(0.16 \%)$ & - & - \\
\hline M47 & - & $2(0.24 \%)$ & - & M97 & - & - & - \\
\hline M48 & $7(1.15 \%)$ & $8(0.95 \%)$ & $1(0.40 \%)$ & M98 & - & $1(0.12 \%)$ & - \\
\hline M49 & $4(0.66 \%)$ & $14(1.67 \%)$ & $1(0.40 \%)$ & M99 & $19(3.13 \%)$ & $1(0.12 \%)$ & $15(6.07 \%)$ \\
\hline M50 & - & $1(0.12 \%)$ & - & M100 & - & - & $4(1.62 \%)$ \\
\hline
\end{tabular}


Although we have explored the issue of sample size in this paper further development of our sampling model would require trying to model the structure of motif variation within Lapita sites. Questions to ask include: are motifs randomly distributed across sites?; to what extent do motifs correlate with potential taphanomic factors (e.g. pot thickness etc)? and does purposive sampling based on sherd density bias our motif sample? Some of these issues may be investigated using sampling experiments on current datasets. However, additional data on Lapita site structure, resulting from large areal excavation is needed before we can confidently assess how well our samples reflect the target population. As Felgate (2003) concluded most of our Lapita samples are very small and it is hard to know how well they usefully represent target populations.

\section{Endnotes}

1. This is extracted in part from a much longer treatment of motif variation and sampling at these sites (Green ms.) currently available as a manuscript, though destined for eventual issuance in the newly instituted University of Auckland Research in Archaeology and Linguistics e-journal for easier permanent access by those who may wish such data and its interpretation. This long article is a highly detailed evaluation of adequacy exhibited by the motif analyses of decorated ceramic collections from three Reef/Santa Cruz Lapita sites in the Outer Eastern Islands of the Solomons which treats each motif listed in Table 2 of this paper separately. This makes it possible not only to identify the set of motifs which prove highly indicative in placing the three sites in their expected chronological order, but also a smaller set of motifs over-represented due to far greater size of the RF-2 assemblage.

2. The population under investigation in each of these cases might be a notional assemblage of ceramic motifs produced during an occupation.

3. Re-sampling was conducted using the re-sampling add-on for Excel by Resampling Stats Inc 2006.

\section{References}

Anson, D. 1986. Lapita Pottery of the Bismarck Archipelago and its affinities. Archaeology in Oceania 21:157-165.

Anson, D. 1987. Reply to Kirch et al. Archaeology in Oceania 22:127-128.

Asch, D. L. and J. W. Mueller 1975. Sampling in archaeology. Tucson: University of Arizona Press.

Best, S. 2002. Lapita: A View from the East. Auckland: New Zealand Archaeological Association Monograph 24.

Chiu, S. 2003. The Socio-Economic Function of Lapita Ceramic Production and Exchange: A Case Study from Site WKO013A, Koné, New Caledonia. Unpublished PhD, University of California Berkeley.

Cochrane, G. W. G. 2003. Artefact attribute richness and sample size adequacy. Journal of Archaeological Science 30(7):837-838.

Donovan, L. J. 1973. A Study of the Decorative System of Potters in the Reefs and Santa Cruz islands. Unpublished Research Essay, University of Auckland.

Felgate, M. 2003. Reading Lapita in Near Oceania: Intertidal Shallow-water Pottery Scatters, Roviana Lagoon, New Georgia, Solomon Islands. Unpublished PhD, University of Auckland.

Grayson, D. K. 1978. Minimum numbers and sample size in vertebrate faunal analysis. American Antiquity 43(1):53-65.

Green, R. C. 1976. Lapita sites in the Santa Cruz Group. In R.C. Green and M.M. Cresswell (eds), Southeast Solomon Islands Cultural History. A Preliminary Survey, pp. 245-265. Wellington: The Royal Society of New Zealand, Bulletin 11.

Green, R. C. 1978. New sites with Lapita Pottery and their Implications for an Understanding of the Settlement of the Western Pacific. Working Papers in Anthropology, Archaeology and Maori Studies, No. 51. Auckland: Department of Anthropology, University of Auckland. 
Green, R. C. 1979. Lapita. In J. Jennings (ed.), Prehistory of Polynesia, pp. 27-60. Cambridge, Mass. : Harvard University Press.

Green, R. C. 1987. Obsidian Results from the Lapita Sites of the Reef/Santa Cruz Islands. In W. Ambrose and J. Mummery (eds), Archaeometry: Further Australasian Studies, pp. 239-249. Canberra: Australian National University.

Green, R. C. 1991a. The Lapita Cultural Complex: Current Evidence and Proposed Models. In P.S. Bellwood (ed.) IndoPacific Prehistory 1990, vol. 2, pp. 295-305. Canberra: Indo-Pacific Prehistory Association Bulletin 11.

Green, R. C. 1991b. A reappraisal of the dating from some Lapita sites in the Reef/Santa Cruz Group of the Southeast Solomon Islands. Journal of the Polynesian Society 100:197-207.

Green, R. C. 1992. Definitions of the Lapita Cultural Complex and its Non-Ceramic Component. In J-C. Galipaud (ed.), Poterie Lapita and Peuplement: Actes du Colloque Lapita, Nouméa, Nouvelle Calédonie, Janvier 1992, pp. 7-20. Nouméa: ORSTOM.

Green, R. C. 2003. The Lapita horizon and traditions - Signature for one set of oceanic migrations. In C. Sand (ed.), Pacific Archaeology: assessments and prospects, pp. 95-120. Nouméa: Service des Musées et du Patrimoine de Nouvelle-Calédonie Volume 15.

Green, R.C. ms. An evaluation of adequacy for motif analyses of decorated ceramic collections from three Reef/ Santa Cruz Lapita sites in the Outer Eastern Islands of the Solomons. [Prepared in November 2006 for submission to an electronic journal]

Green, R. C., M. D. Jones and P. J. Sheppard n.d. The absolute dating and reconstructed environmental context of the SZ-8 (Nanggu) dentate-decorated Lapita site of the Reef Santa Cruz region of the Outer Eastern Islands of the Solomon Islands.

Green, R. C. and A. K. Pawley 1999. Early Oceanic architectural forms and settlement patterns: Linguistic, archaeological and ethnological perspectives. In R. Blench and M. Spriggs (eds), Archaeology and Language III: Artefacts, Languages and Texts, pp. 31-39. London: Routledge.

Jones, G. T., D. K. Grayson and C. Beck 1983. Artifact class richness and sample size in archaeological surface assemblages. Anthropological papers-Museum of Anthropology, University of Michigan (72):55-74.

Jones, M. D., F. J. Petchey, R. C. Green, P. J. Sheppard and M. Phelan 2007. The Marine $\Delta$ R for Nenumbo (Solomon Islands): a case study in calculating reservoir offsets from paired sample data. Radiocarbon 49(1).

Kintigh, K. W. 1989. Sample size, significance, and measures of diversity. Quantifying Diversity in Archaeology, pp. 25-36. Cambridge, Eng. : Cambridge University Press.

Kirch, P. V. 1997. The Lapita Peoples: Ancestors of the Oceanic World. Cambridge: Blackwell.

Kirch, P. V. M. Allen, V. Butler and T. Hunt 1987. Is there an early Far Western Lapita province? Sample size effects and new evidence from Eloaua Island. Archaeology in Oceania 22:123-128.

Meltzer, D. J., R. D. Leonard and S. K. Stratton 1992. The relationship between sample size and diversity in archaeological assemblages. Journal of Archaeological Science 19(4):375-387.

Orton, C. 2000. Sampling in archaeology Cambridge: Cambridge University Press.

Plog, S., 1976. Measurement of prehistoric interaction between communities. In K.V. Flannery (ed.), The Early Mesoamerican Village, pp. 136-158. New York: Academic Press.

Redman, C. L. 1974. Archeological sampling strategies. New York: Addison-Wesley.

Sheppard, P. J. 1993. Lapita lithics: trade/exchange and technology. A view from the Reefs/Santa Cruz. Archaeology in Oceania 28(3):121-137.

Sheppard, P. J. and R. C. Green 1991. Spatial analysis of the Nenumbo (SE-RF-2) Lapita site, Solomon Islands. Archaeology in Oceania 26:89-101.

Sheppard, P.J. and R. Walter 2006. A revised model of Solomon Islands Cultural History. Journal of the Polynesian Society 115:47-76. 